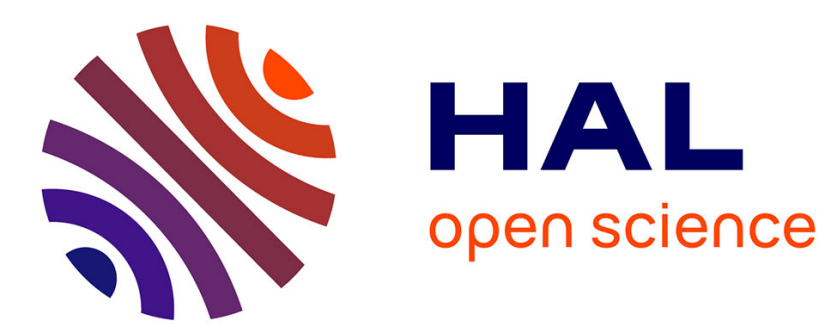

\title{
Mechanical properties of unidirectional, porous polymer/ceramic composites for biomedical applications
}

Jordi Seuba, Eric Maire, Jérôme Adrien, Sylvain Meille, Sylvain Deville

\section{To cite this version:}

Jordi Seuba, Eric Maire, Jérôme Adrien, Sylvain Meille, Sylvain Deville. Mechanical properties of unidirectional, porous polymer/ceramic composites for biomedical applications. Open Ceramics, 2021, 8, pp.100195. 10.1016/j.oceram.2021.100195 . hal-03297014v2

\section{HAL Id: hal-03297014 \\ https://hal.science/hal-03297014v2}

Submitted on 6 Dec 2021

HAL is a multi-disciplinary open access archive for the deposit and dissemination of scientific research documents, whether they are published or not. The documents may come from teaching and research institutions in France or abroad, or from public or private research centers.
L'archive ouverte pluridisciplinaire HAL, est destinée au dépôt et à la diffusion de documents scientifiques de niveau recherche, publiés ou non, émanant des établissements d'enseignement et de recherche français ou étrangers, des laboratoires publics ou privés. 


\title{
Mechanical properties of unidirectional, porous polymer/ceramic composites for biomedical applications
}

\author{
Jordi Seuba $^{\mathrm{b}}$, Eric Maire ${ }^{\mathrm{b}}$, Jérôme Adrien ${ }^{\mathrm{b}}$, Sylvain Meille ${ }^{\mathrm{b}}$, Sylvain Deville ${ }^{\mathrm{a}, *}$ \\ ${ }^{a}$ Université de Lyon, Université Claude Bernard Lyon 1, CNRS, Institut Lumière Matière, 69622, Villeurbanne, France \\ ${ }^{\mathrm{b}}$ Univ Lyon, INSA Lyon, UCBL, CNRS, MATEIS UMR5510, 69621 Villeurbanne, France
}

\section{A R T I C L E I N F O}

\section{Keywords:}

Ice-templating

Porous composites

Yttria-stabilized zirconia (YSZ)

Polycaprolactone (PCL)

Mechanical properties

\begin{abstract}
A B S T R A C T
The addition of a ductile phase to a porous ceramic can help overcome the brittleness of ceramics. Yet, most studies so far have focused on the processing and characterization of dense composites. Alternatively, unidirectional pores can improve the strength of porous ceramics. Here we combine the two approaches and show a simple processing strategy to obtain highly porous, unidirectional ceramic/polymer composites. We infiltrated ice-templated porous zirconia scaffolds with a polymer or a polymer solution. After centrifugation and evaporation of the solvent, porous ceramic composites with a porosity greater than $60 \%$ were obtained. Our results demonstrate that the addition of a ductile polymer (PCL) can increase both the strength and the toughness of the composites while maintaining a high porosity, whereas a brittle polymer (epoxy) has seemingly no impact on the fracture properties. This approach could provide porous materials that are easier to handle for biomedical applications.
\end{abstract}

\section{Introduction}

Highly porous ceramics are mostly used for their high permeability, low thermal conductivity, or open porosity which makes them useful in tissue engineering [1,2], as catalyst supports [3], photocatalysis [4], oil/water separation [5], or in filtration applications [6]. However, their presence in technological fields where these functional properties have a crucial importance -energy harvesting, environment, or biomedicine-is still moderate. One of the main barriers to a wider application is the inherent brittleness of ceramic materials, resulting in brittle fracture at low load levels. Highly porous ceramics are often so weak that even their handling can be challenging.

The interplay between strength and toughness in ceramics make both properties mutually exclusive and has been a fruitful research area in the last decade. Extensive work has been done to improve the fracture toughness of ceramics with a moderate impact on strength. The explored strategies are as diverse as introducing residual compressive stresses [7], making stronger interfaces [8], introducing a polymeric [9] or metal phase [10], or mimicking the microstructure of natural composite materials $[11,12]$. However, the majority of the research has been focused on dense ceramics and comparatively little has been done on their porous counterparts.
The most common approach to improve the mechanical properties of porous ceramics is the incorporation of a ductile organic phase [13], to partially or completely fill the porosity. It is nevertheless crucial to have a continuous ceramic scaffold first to provide strength and rigidity to the material. A coated ceramic scaffold is thus stronger and more rigid than a porous blend of materials where ceramic particles are distributed in the polymer phase. The ceramic scaffold provides high stiffness and stress resistance while the polymeric phase provides a higher flaw tolerance. One simple way to obtain such materials is to infiltrate a sintered or partially sintered ceramic with an organic phase. Because of their interest for biomedical applications, most studies have focused on biodegradable synthetic polymers as polycaprolactone (PCL) [14], polylactide-coglycolide (PLGA) [15] or poly (D-L-lactic acid)(PDLLA) [16]. In all these studies, however, the initial porous structure was isotropic, with no preferential orientation of the macropores.

Ice-templating (or freeze-casting) is a processing technique for macroporous materials [17], investigated for its potential in applications as diverse as sensors [18], filtration [19], oil absorption [20], $\mathrm{CO}_{2}$ capture and energy storage [21], microwave absorption [22], tissue engineering [23], oxygen transport membranes [24], sound adsorber [25], solid oxide fuel cells [26], or batteries [27]. The process consists in freezing particle suspensions, which induces a segregation of particles

\footnotetext{
* Corresponding author.

E-mail address: sylvain.deville@univ-lyon1.fr (S. Deville).
} 
by the solidification front. After solidification, the frozen solvent is removed, leaving pores which morphologies are a replica of the sublimated crystals. Finally, the green body is sintered to consolidate the microstructure. A feature of this processing method that is both an advantage and a drawback is the mechanical anisotropy exhibited by the unidirectional macroporous structure, similar to honeycomb structures. Although this anisotropy offers a reinforcement in the direction parallel to the pores [28], the weaker resistance in the perpendicular direction prevents their use in applications with a multiaxial stress field.

Several groups have infiltrated polymers into porous, ice-templated ceramic scaffolds, resulting in alumina/epoxy [29,30], alumina/UDMA-TEGDMA [31], alumina/PMMA [32], or alumina/resin composites for dentistry applications [33]. These studies revealed the role of residual porosity-acting as defects and thus detrimental to the mechanical properties-as well as the role of the mechanical properties of the polymer phase and its adhesion to the ceramic surface. Without a good adhesion (e.g., with epoxy), delamination occurs easily at the polymer/ceramic interface $[29,30]$. A better control of the adhesion can be achieved with PMMA [32]. However, in all these studies, the final composites are nearly dense, with a residual porosity of only a few percent.

Comparatively, relatively little studies can be found on the processing and mechanical properties of anisotropic, highly porous ceramic/ polymer composites. The only study addressing the processing and characterization of highly porous ice-templated porous composites is the work of Flauder et al. [34]. Ice-templated calcium phosphates (TCP) scaffolds were infiltrated with a low amount (1-5\%) of polycaprolactone (PCL), to obtain materials for bone replacement applications. The objective was thus to improve the mechanical properties (strength, toughness) of the material while preserving the open and directional macroporosity for cells penetration. Several infiltration cycles were performed to fill the micropores within the ceramic walls and ultimately create a thin polymer coating at the surface of the ceramic walls. A noticeable improvement of strength and damage tolerance was observed, due to the elastic and plastic deformation of the polymer, as expected, but also formation of polymer fibrils creating local bridges in the structure. The surprising increase in strength was possibly explained by the cold drawing and hardening of PCL fibers during failure. PCL fibers provide load transfer capacities to the structure, across the crack flanks, decreasing stress level at the crack tip. Both the compressive and flexural strength values were reported.

Here, we followed a similar approach with a stronger ceramic (yttriastabilized zirconia) and investigated the mechanical properties of highly porous ceramic-polymer composites with unidirectional porosity. We developed a route to process such composites by partially infiltrating ice-templated scaffolds with a dilute polymer solution. We characterized the impact of polymer infiltration on microstructure and mechanical properties (flexural strength, work of fracture, toughness), and assessed the effect of two polymers with different mechanical behaviors: brittle (Epoxy) or ductile (PCL). We characterized the damage mechanisms by bending some of our notched samples in situ in a laboratory tomograph.

\section{Materials and methods}

\subsection{Processing the composite}

Ceramic scaffolds with unidirectional porosity were produced by icetemplating as described in previous work [28]. First, water-based solutions were prepared by mixing $3 \mathrm{~mol} \%$ yttria-stabilized zirconia (TZ-3YS, Tosoh, Tokyo, Japan) at $50 \mathrm{wt} \%$ solid loading, $0.75 \mathrm{wt} \%$ of dispersant (Prox B03, Synthron, Levallois- Paris, France), and $3 \mathrm{wt} \%$ of organic binder PVA (PVA2810, Wacker, Burghausen, Germany). All the percentages are referred to the total solid content of the dispersion. Afterwards, the slurry was ball milled (24 h), magnetically stirred, and deaired (15 min).

Ice-templating was performed by pouring $10 \mathrm{ml}$ of slurry into a PTFE mold (20 mm diameter and $25 \mathrm{~mm}$ height) placed on top of a copper plate and freezing from the bottom to the top. The temperature was controlled by circulating silicone oil regulated by a cryothermostat (Model CC 905, Hubert, Offenburg, Germany) through the copper plate. The cooling rate was set at $2{ }^{\circ} \mathrm{C} / \mathrm{min}$. After complete solidification, samples were demolded and freeze-dried for at least $48 \mathrm{~h}$ in a commercial freeze-dryer (Free Zone 2.5 Plus, Labconco, Kansas City, Missouri, USA).

The subsequent sintering cycle involved first removal of organic components, which was achieved by heating the samples from room temperature to $500{ }^{\circ} \mathrm{C}$ at a rate of $3{ }^{\circ} \mathrm{C} / \mathrm{min}$ and holding them at this temperature for $5 \mathrm{~h}$. Then, samples were sintered at $1400{ }^{\circ} \mathrm{C}$ (heating rate of $5{ }^{\circ} \mathrm{C} / \mathrm{min}$ ) for $3 \mathrm{~h} .2 \mathrm{~mm}$ of the bottom of each sample were cut off to remove the portion of the samples with an initial porosity gradient [35]. Finally, between 5 and 8 bars were cut from each ice-templated monolith with dimensions of $14 \times 3 \times 3 \mathrm{~mm}^{3}$ and a longitudinally oriented porosity.

Sintered ice-templated bars were infiltrated with two different polymers, polycaprolactone (Polycaprolactone Aldrich 440744-500G, $\mathrm{M}_{n}=80,000 \mathrm{~g} / \mathrm{mol}$, Sigma-Aldrich) or epoxy (Epotek 301, Billerica, Massachussetts, USA). The PCL infiltration process consisted in the preparation of PCL solutions with different concentration (4 and $8 \mathrm{wt} \%$ ) in ethyl acetate (anhydrous, 99.8\%, Sigma-Aldrich) at $80{ }^{\circ} \mathrm{C}$. Afterwards, the specimens were placed in a PTFE mold and the PCL solution poured on it. The process was performed under vacuum to facilitate the infiltration and removal of the residual air entrapped in the samples. After $20 \mathrm{~min}$ of vacuum infiltration the samples were placed on an absorbent paper for $24 \mathrm{~h}$ to ensure the entire evaporation of the solvent. Infiltration with epoxy was performed following a similar procedure: a mix of resin and hardener (80-20 $\mathrm{wt} \%$ respectively) was poured under vacuum in a PTFE mold with the ice-templated bars on it. Afterwards, the excess of epoxy was removed from the samples using a tabletop centrifuge at different centrifugal speeds $(2500,5000,7500$, and 10000 $\mathrm{rpm})$.

\subsection{Characterization}

The apparent density of ice-templated bars $(\rho)$ was measured as total weight divided by external volume $(\mathrm{V})$. The porosity $(\mathrm{P})$ was determined from these measurements by considering $6.05 \mathrm{~g} / \mathrm{cm}^{3}$ as theoretical density $\left(\rho_{0}\right)$ for YSZ. The porosity was determined from the apparent density as:

$P(\%)=1-\frac{\rho}{\rho_{0}}$

The volume (OC) of the scaffold occupied by the organic after infiltration was determined by:

$O C(\%)=\frac{m_{1}-m_{0}}{\rho_{\text {organic }} V}$

where $m_{1}$ is the mass of the infiltrated sample after solvent evaporation and $\rho_{\text {organic }}$ is the theoretical density of the infiltrated organic $\left(\rho_{P C L}=\right.$ $1.145 \mathrm{~g} / \mathrm{cm}^{3}$ and $\rho_{\text {Epoxy }}=1.25 \mathrm{~g} / \mathrm{cm}^{3}$ ). Microstructural characterization was investigated on fracture surfaces by scanning electron microscopy (FEI XL30 ESEM FEG).

Flexural strength (Eq. (3)) of infiltrated and non-infiltrated bars was evaluated in a 4points bending test using a hydraulic universal testing machine (Instron 8502) equipped with a $10 \mathrm{kN}$ cell load at a constant 
cross-head speed of $0.2 \mathrm{~mm} / \mathrm{min}$. The sample deflection was measured by a linear variable differential transformer (LVDT) with micrometer accuracy. The flexural strength $\sigma_{f}$ is given by:

$\sigma_{f}=\frac{3 F\left(L-L^{\prime}\right)}{4 b h^{2}}$

where $F$ is the applied load, $b$ and $h$ the width and height of the sample, $L$ and $L^{0}$ the respective lower an upper span. The fracture toughness $\left(K_{I c}\right)$ was calculated by Eq. (4), from tests on notched samples:

$K_{I c}=Y \sigma \sqrt{\pi a}$

where $\sigma_{f}$ is the flexural stress, $Y=1.64$ a geometrical factor, and $a$ is the notch length. Work of fracture $G$ values were obtained from the curves obtained during the 4-points bending test measuring the area below the force-displacement curve up to the maximum stress $\left(G_{\max }\right)$ or to a given value of strain ( $G_{7 \%}$ on typically $18 \times 3 \times 4 \mathrm{~mm}^{3}$ samples) divided by the remaining sample section in notched samples.

\subsection{X-ray tomography}

$\mathrm{X}$-ray tomography was used to image the crack path in situ and better understand the role of the microstructural features on the crack propagation. Of particular interest was the role of the orientation domains of the lamellar structure of ice-templated samples [36,37]. Because of the high absorption of X-rays by zirconia, we could not image cracks in zirconia composites. We choose instead to prepare similar composites from ice-templated alumina, the later having a much lower absorption coefficient. Ice-templated alumina samples were prepared with the exact same conditions than these previously described in YSZ, yielding similar microstructure. We developed a simple setup for the tomograph to initiate and propagate a crack in situ in a bent, notched sample (see the radiograph shown in Fig. 1). The notched sample is placed between two fixtures, inside a custom compression testing device, described in Ref. [38]. The sample is clamped in the fixed lower fixture, while its upper part is in contact with the inclined surface of the upper fixture. A vertical displacement of this inclined surface induces a bending stress on

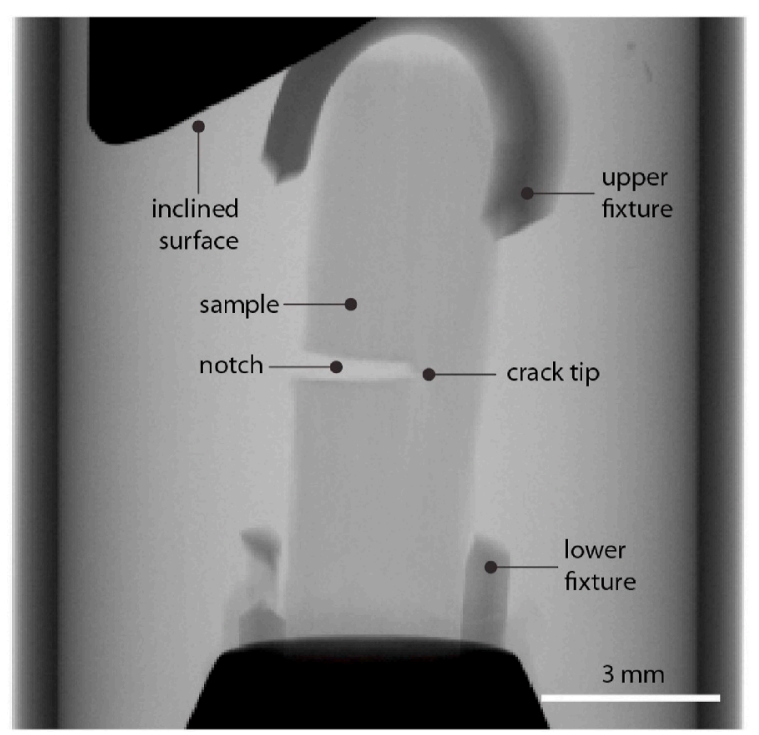

Fig. 1. Detail of the sample and set-up used for the in-situ bending test in the Xray tomograph. The notched sample is placed vertically between two fixtures. Because of the inclined surface, the displacement of the upper fixture bends the sample, which eventually initiates a crack. () (2020) J. Seuba et al. (10.6084/ m9.figshare.15022263) CC BY 4.0 license https://creativecommons.org/lice nses/by/4.0/. the sample, and thus initiates the propagation of the crack. The crack in the notch area remains at an almost constant position, which facilitates the imaging. Although we cannot precisely estimate the stress level on the sample, this approach let us identify the role of the orientation domains on the crack propagation, for which the exact stress level is not needed.

The imaging was performed on a Vtomex tomograph (GE Phoenix Xray $\mathrm{Gmbh}$ ) operated at $90 \mathrm{keV}, 240 \mu \mathrm{A}$ intensity. For these measurements, 1000 radiographs were recorded during the $360^{\circ}$ rotation with an exposure time of $333 \mathrm{~ms}$ each, resulting in an acquisition time of roughly $20 \mathrm{~min}$. The obtained voxel size was $3 \mu \mathrm{m}$.

\section{Results and discussion}

\subsection{YSZ/PCL composites}

Ice-templating allows the processing of YSZ samples with reproducible microstructure and porosity. The sintered ceramic monoliths fabricated in this study have a total porosity of $77.1 \pm 2 \%$ and the scaffolds that were cut off from these same monoliths exhibit a comparable total porosity of $78.2 \pm 0.7 \%$. This slight decrease of porosity when removing the lower part of the sample can be explained by the higher density of this initial region. The velocity of the ice front in the transient regime is high, which results in the engulfment of a larger fraction of particles-and thus a lower porosity in the final material [35]. Sedimentation may also explain this slight decrease of porosity in this region.

Fig. 2-A shows a close-up view, as observed on SEM micrographs, of the unidirectional porosity created by the ice-templating process with rough walls that replicates the dendritic morphology of the ice crystals. After infiltration by a $4 \mathrm{wt} \%$ PCL solution ( 1 cycle), a thin polymer layer is homogeneously deposited on the ceramic walls without filling the porosity (Fig. 2-B).

We investigated the effect of PCL infiltration on porosity (Table 1). As expected, the measured organic content increased with the number of infiltration cycles. In samples infiltrated with a $4 \mathrm{wt} \%$ PCL solution, the organic content increases from $4.0 \pm 0.1 \%$ to $10.1 \pm 0.7 \%$ when the number of cycles increases from 1 to 4 . Conversely, the porosity decreases linearly with the number of infiltration cycles, as shown in Fig. 3.

Specimens where the amount of PCL initially infiltrated in the specimens is the same $(4 \times 4 \mathrm{wt} \%$ PCL vs $2 \times 8 \mathrm{wt} \%$ PCL and $2 \times 4 \mathrm{wt} \%$ PCL vs $1 \times 8$ wt $\%$ PCL) exhibited a comparable measured organic content and porosity. We did not investigate infiltrations with more concentrated polymer solutions, as the increase of the viscosity with the PCL concentration became problematic. A more viscous solution is more difficult to deposit homogeneously and thus creates clogged pores, as reported by Peroglio et al. [39] in porous biphasic calcium phosphates processed by organic burn-out and similar PCL infiltration conditions. Our results are also in agreement with the optimal conditions determined by Flauder et al. [34], who selected $4 \mathrm{wt} \%$ as the optimal PCL concentration in acetone for infiltration. Although this choice was not justified by the authors, it is likely related to the same infiltration constraints. Despite the solvent in both studies being different, a too high polymer concentration is deleterious for this infiltration approach

We can also note, from the porosity values reported in Table 1 , that the standard deviation values of the porosity are small (less than $1 \%$ ). Porosity differences between similar samples have two possible origins: differences in the amount of porosity in the icetemplated ceramic scaffolds, and different outcomes of the polymer infiltration procedure (repeated in some cases up to 8 times). Ice-templating is a robust approach: when the same suspension is frozen under the same conditions to prepare several samples, the final porosity range (after drying and sintering) is narrow, typically within $1 \%$ [28]. This value is similar to the values measured in the final composites, which therefore indicate that the polymer infiltration procedure is quite robust too, and produce consistent results between samples infiltrated in similar conditions. 
A

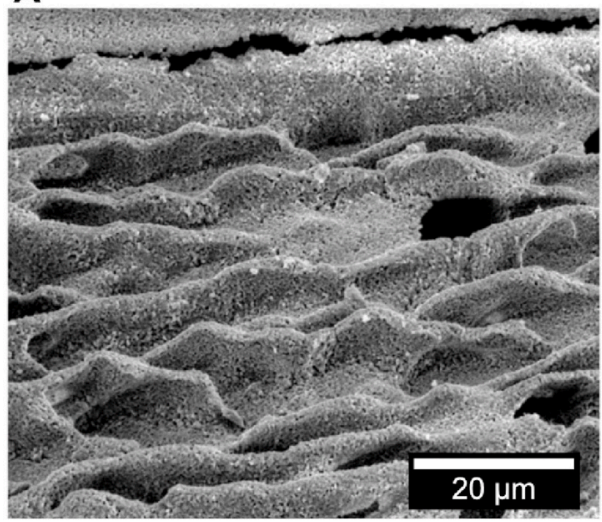

B

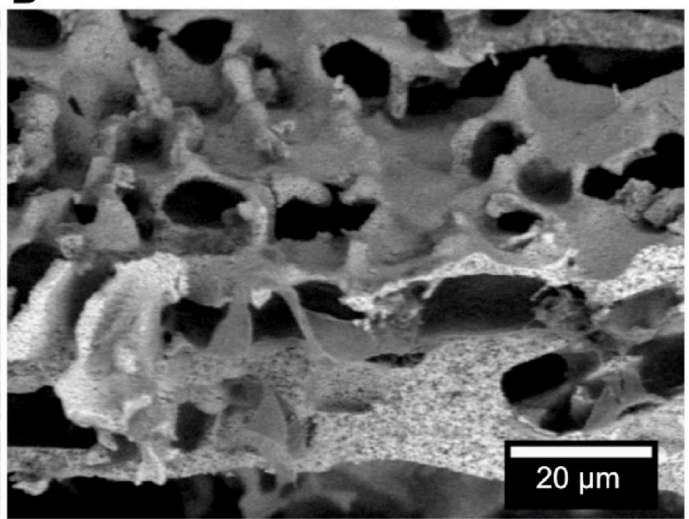

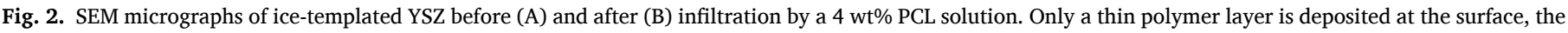

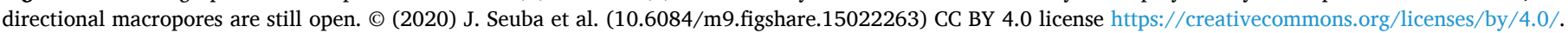

Table 1

Open and close porosity of PCL/YSZ composites for different number of infiltration cycles and different PCL concentration of the infiltration solution.

\begin{tabular}{lllll}
\hline $\begin{array}{l}\text { PCL concentration } \\
\text { (wt.\%) }\end{array}$ & Cycles & $\begin{array}{l}\text { Total } \\
\text { porosity (\%) }\end{array}$ & $\begin{array}{l}\text { Ceramic } \\
\text { content (\%) }\end{array}$ & $\begin{array}{l}\text { Organic } \\
\text { content (\%) }\end{array}$ \\
\hline 0 & 0 & $78.4 \pm 3$ & $21.6 \pm 0.9$ & 0 \\
4 & 1 & $75.8 \pm 1$ & $20.2 \pm 0.8$ & $4.0 \pm 0.1$ \\
4 & 2 & $73.5 \pm 0.4$ & $19.9 \pm 0.3$ & $6.6 \pm 0.3$ \\
4 & 3 & $70.7 \pm 0.1$ & $19.2 \pm 0.7$ & $10.1 \pm 0.7$ \\
4 & 4 & $66.5 \pm 3$ & $20.6 \pm 0.7$ & $12.9 \pm 2$ \\
8 & 1 & $73.3 \pm 0.8$ & $21.6 \pm 0.7$ & $6.0 \pm 0.4$ \\
8 & 2 & $67.0 \pm 2$ & $20.5 \pm 0.6$ & $12.5 \pm 1$ \\
\hline
\end{tabular}

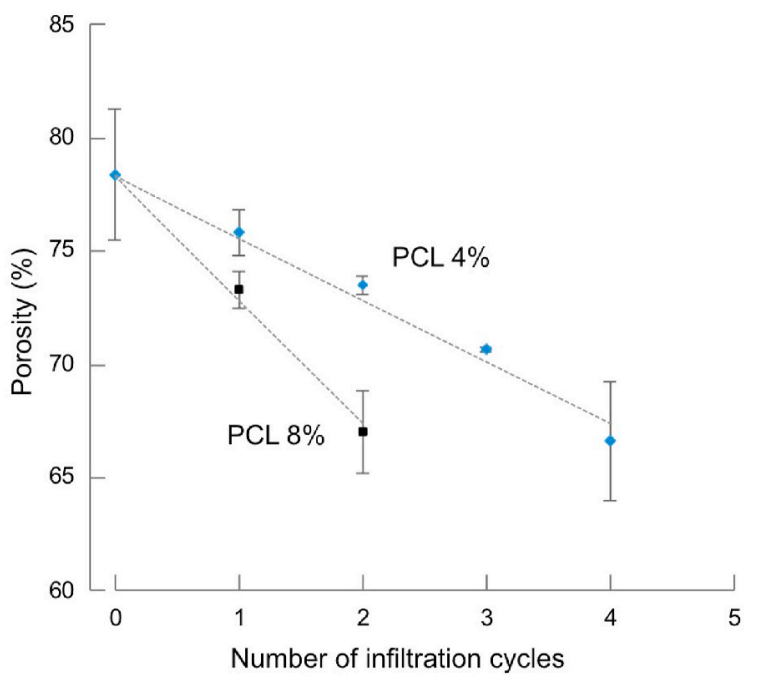

Fig. 3. Porosity content vs. number of infiltration cycles, for PCL solutions with different PCL concentrations. Dashed lines are a guide for the eyes. () (2020) J. Seuba et al. (10.6084/m9.figshare.15022263) CC BY 4.0 license https://cre ativecommons.org/licenses/by/4.0/.

Fig. 4 shows representative stress-strain curves for ice-templated bars with no infiltration, 1 infiltration cycle, and 4 infiltration cycles (4\% PCL solution) in a 4-points bending test. The non-infiltrated specimens show the typical response of a porous ceramic material, with an elastic behavior until catastrophic failure. Some fracture events may occur before the maximum stress is reached, leading to the stochastic shape of the compression curve. These events are most likely caused by the fracture of the internal struts in the porous structure.
Both PCL-infiltrated scaffolds (1 and 4 infiltration cycles) show a linear elastic behavior in the first stage, similar to non-infiltrated samples. However, once the ceramic is broken (at the end of the linear elastic region), polymer-infiltrated scaffolds exhibited a plastic stage (plateau) at a load level which depends on the amount of polymer in the porous composite. This effect is also quantified by the work of fracture differences obtained in each infiltration condition at a similar strain value of $7 \%$ (as calculated using the linear elastic assumption) (Table 2). For instance, samples infiltrated 4 times exhibited a $G_{7 \%}$ significantly higher than the samples infiltrated only once $\left(203 \pm 30 \mathrm{~J} \mathrm{~m}^{-2}\right.$ vs. $\left.97 \pm 20 \mathrm{~J} \mathrm{~m}^{-2}\right)$.

The impact of the amount of polymer on fracture toughness $\left(K_{I c}\right)$, and work of fracture at maximum stress $\left(G_{\max }\right)$ is noticeable (Table 2). The toughness $K_{I c}$, for example, is twice greater after 4 infiltration cycles $\left(0.40 \pm 0.03 \mathrm{MPa} \mathrm{m}^{1 / 2}\right.$ after infiltration vs. $0.23 \pm 0.04 \mathrm{MPa} \mathrm{m} \mathrm{m}^{1 / 2}$ before), despite a low amount of polymer introduced in the structure. This implies that the initiation of the fracture is not determined by just the amount of ceramic in the scaffold, since this amount is the same for the three conditions ( 0,1 and 4 infiltration cycles). The addition of a polymer improved all the mechanical properties reported here. Once the fracture is initiated, the amount of organic phase also controls the resistance to crack propagation, as evidenced by the increase of $G_{7 \%}$ values with infiltration cycles.

The strength of the composites seems to increase (approx. 40\%, from $4.7 \pm 0.8 \mathrm{MPa}$ to $6.5 \pm 1 \mathrm{MPa}$ with the amount of polymer infiltrated within the samples (Table 2). Such increase has been reported previously [34] in similar composites. However, the standard deviations values associated to the strength values are relatively large and prevent concluding in a quantitative estimation of the strength increase at this point.

This improvement of properties has several possible origins, including the redistribution of stress in the solid phase as well as a strengthening of the walls due to the sealing of defects in the walls, as reported previously [34]. However, the difference of Young's modulus between zirconia and PCL is enormous, the redistribution of stress is therefore unlikely here. This behavior is not observed in dense ceramic/polymer composites [40], where the presence of a soft polymer has no positive effect on the initiation of fracture.

Besides the effects on the mechanical properties (crack propagation), polymer infiltration also affects the handling and integrity of the specimens. While non-infiltrated samples formed a lot of debris and collapse in multiple parts during mechanical testing, the PCL-infiltrated ones retained good integrity even when damaged (Fig. 5). Unfortunately, it was not possible to evaluate the maximum deformation before final fracture because the samples came into contact with the sample holder. Peroglio et al. [14] reported residual deflection higher than $1 \mathrm{~mm}$ (for a sample size of $6 \times 10 \times 60 \mathrm{~mm}^{3}$ ) before total fracture in samples with 

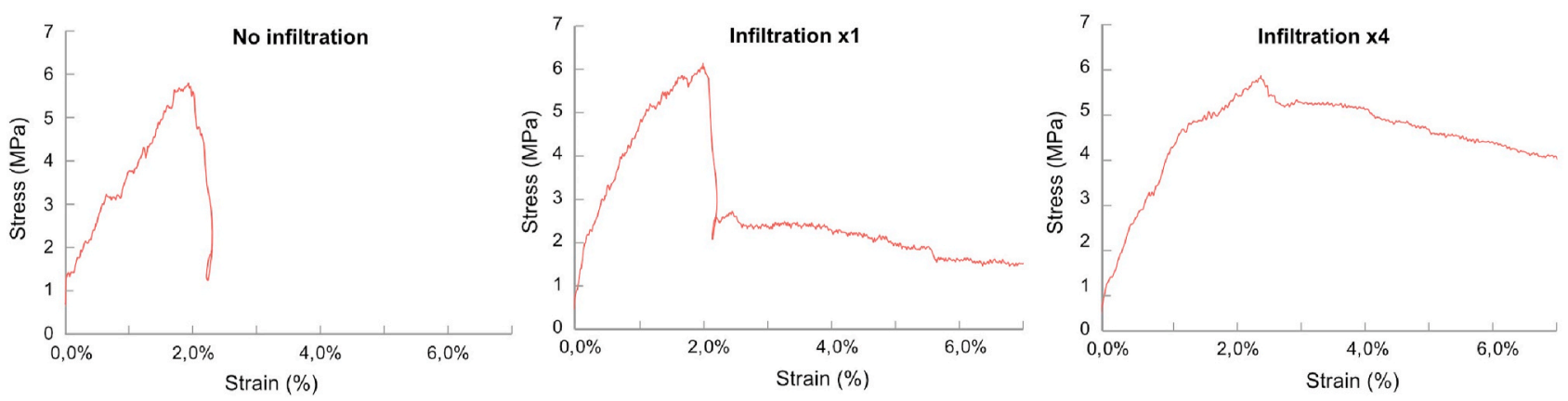

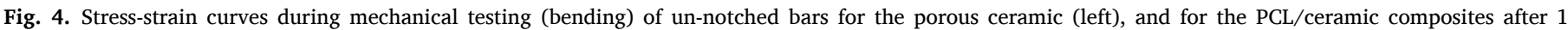

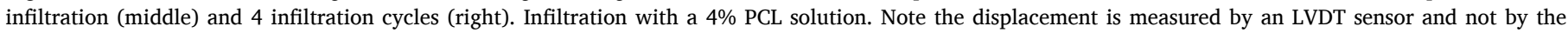

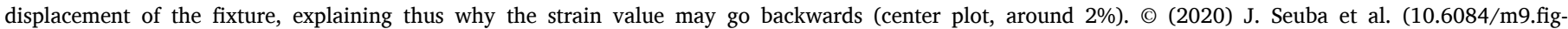
share.15022263) CC BY 4.0 license https://creativecommons.org/licenses/by/4.0/.

Table 2

Mechanical properties of the porous ceramic and PCL-infiltrated composites (1 and 4 infiltration cycles with a $4 \mathrm{wt} \%$ PCL solution). 5 samples were tested for each condition. $\sigma_{f}$ and strain at failure: Un-notched samples. $K_{I c}, G_{\max }$ and $G_{7 \%}$ : notched samples.

\begin{tabular}{llllll}
\hline $\begin{array}{l}\text { Infiltration } \\
\text { cycles }\end{array}$ & $\begin{array}{l}\sigma_{f} \\
(\mathrm{MPa})\end{array}$ & $\begin{array}{l}\text { Strain at } \\
\text { failure (\%) }\end{array}$ & $\begin{array}{l}K I c(M P a \\
m 1 / 2)\end{array}$ & $\begin{array}{l}G \max (J \cdot \\
m-2)\end{array}$ & $\begin{array}{l}G 7 \%(J . \\
m-2)\end{array}$ \\
\hline 0 & $4.7 \pm$ & $2.1 \pm 0.4$ & $0.23 \pm$ & $35 \pm 7$ & - \\
& 0.8 & & 0.04 & & \\
1 & $5.8 \pm$ & $2.4 \pm 0.4$ & $\begin{array}{l}0.26 \pm \\
0.4\end{array}$ & & 0.03 \\
4 & 0.4 & & & \\
& $6.5 \pm 1$ & $2.7 \pm 0.4$ & $0.40 \pm$ & $66 \pm 10$ & $203 \pm 30$ \\
& & & 0.03 & & \\
\hline
\end{tabular}

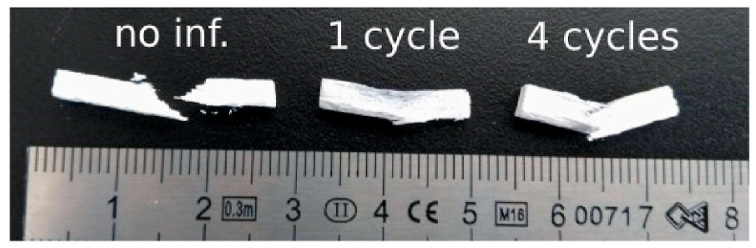

Fig. 5. Samples after mechanical testing. Porous ceramic (left) and composite after 1 (middle) and 4 (right) infiltration cycles. The porous composites are still holding as one piece after testing. The samples are from the tests reported in Fig. 4. (C) (2020) J. Seuba et al. (10.6084/m9.figshare.15022263) CC BY 4.0 license https://creativecommons.org/licenses/by/4.0/.

comparable microstructures.

The toughening effect obtained is intrinsic to the introduction of a highly deformable polymeric phase, which holds the structure together even when the ceramic structure collapses [41]. This mechanism is analogous to the extensively reported crack bridging effect observed in cancellous bone $[42,43]$. In the first stage, the ceramic scaffold withstands the stresses until its failure at a limited strain. Afterwards, in the plastic stage, the polymer phase controls the crack propagation until the polymer reaches its characteristic elongation to fracture producing a crack bridging effect. In our samples, PCL fibrils act in ice-templated scaffolds (see Fig. 6 for a SEM micrograph of these fibrils in our material after fracture) like collagen fibrils in human bone. A similar effect

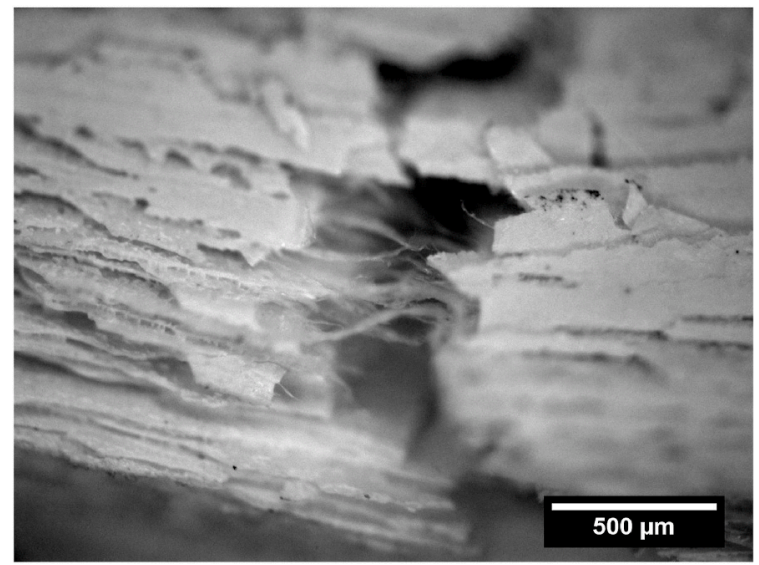

Fig. 6. Close-up view of crack bridging by PCL fibrils after crack propagation in a PCL/YSZ composite. (c) (2020) J. Seuba et al. (10.6084/m9.figshare.15022263) CC BY 4.0 license https://creativecommons.org/lice nses/by/4.0/.

has been shown by Currey et al. [44], who observed that the post-yield strain of bone is highly dependent on collagen content. The key mechanism responsible for the improvement of the mechanical properties in these highly porous materials is therefore the load redistribution enabled by the continuous polymer phase.

\subsection{YSZ/epoxy composites}

Fig. 7 shows micrographs of YSZ ice-templated scaffolds after the epoxy impregnation and centrifugation. Similarly to the PCL infiltrated samples, the epoxy is deposited onto the rough ceramic walls without filling the microporosity. However, the epoxy is too viscous to be removed from the samples, which generates a clogged porosity in some parts of the sample.

We investigated the effect of centrifugal speed on porosity (Table 3). The porosity increases with the centrifugal speed (Fig. 8). The infiltrated polymer is more easily removed from the sample as the centrifugal speed increases. It is thus a simple way to control the amount of polymer deposited into the porous ceramic scaffold.

During the 4-points bending tests, epoxy-YSZ composites exhibited a 
A

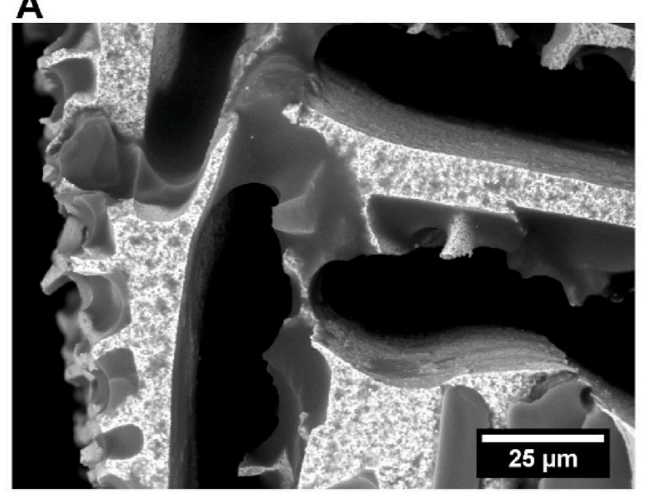

B

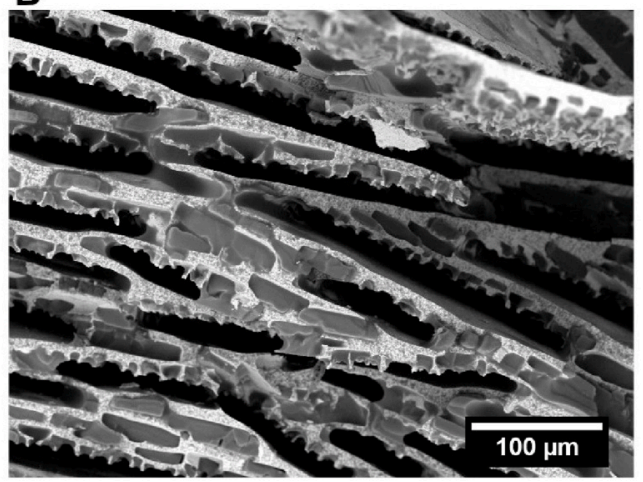

Fig. 7. SEM micrographs of epoxy/YSZ composites. Because of its higher viscosity, the epoxy is not deposited homogeneously through the sample. Small macropores are filled with epoxy. () (2020) J. Seuba et al. (10.6084/m9.figshare.15022263) CC BY 4.0 license https://creativecommons.org/licenses/by/4.0/.

Table 3

Variation of porosity with centrifugal speed after infiltration of the epoxy into the YSZ samples. YSZ/epoxy composites.

\begin{tabular}{lllll}
\hline $\begin{array}{l}\text { Centrifugal } \\
\text { speed }\end{array}$ & $\begin{array}{l}\text { Ceramic content } \\
(\%)\end{array}$ & $\begin{array}{l}\text { Polymer content } \\
(\%)\end{array}$ & $\begin{array}{l}\text { Porosity } \\
(\%)\end{array}$ & $\begin{array}{l}\sigma_{f} \\
(\mathrm{MPa})\end{array}$ \\
\hline 2500 & $20.7 \pm 1.0$ & $34.5 \pm 5$ & $44.8 \pm 5$ & $26 \pm 4$ \\
5000 & $20.0 \pm 0.8$ & $27.2 \pm 0.3$ & $52.9 \pm 0.3$ & $15 \pm 6$ \\
7500 & $20.0 \pm 0.8$ & $22.1 \pm 1$ & $58.0 \pm 1$ & $12 \pm 4$ \\
10000 & $22.2 \pm 0.9$ & $15.2 \pm 1$ & $62.5 \pm 2$ & $8.8 \pm 2$ \\
\hline
\end{tabular}

typical brittle linear elastic behavior similar to non-infiltrated samples. The flexural strength of the specimens centrifuged between $2500 \mathrm{rpm}$ and $10000 \mathrm{rpm}$ ranges from $26 \pm 4 \mathrm{MPa}$ to $8.8 \pm 2 \mathrm{MPa}$, for samples with porosities varying from $44.8 \pm 5 \%$ and $62.5 \pm 2 \%$ (Table 3 ). The porosity in turn controls the strength of the epoxy-based composites. At low centrifugation speed, the centrifugal forces are not enough to spread and remove the epoxy from the sample. The epoxy therefore completely fills parts of the pores. This type of defect affects the microstructural homogeneity of the sample and increases the effective area that withstands the load.

We further explored the possibility to modify simultaneously crack initiation and propagation by infiltrating both polymers in two steps. First, the ceramic samples were infiltrated with epoxy with the procedure previously described. Second, the epoxy-YSZ porous composite was vacuum-infiltrated with a PCL solution. As we expected, the resultant microstructure exhibited an epoxy layer which does not bond with the ceramic scaffold, and a PCL coating on top of that (Fig. 9). The mechanical properties are only marginally improved by the dual infiltration (Tab 4). The YSZ/epoxy composites, however, show a brittle behavior while the dual infiltrated samples are more ductile.

The stress-strain curves of the un-notched samples (under flexion), which properties are reported in Tab 4, are shown in Fig. 10. The figure compares the mechanical behavior of the porous composites (with epoxy, PCL, or both) obtained in this work with a non-infiltrated

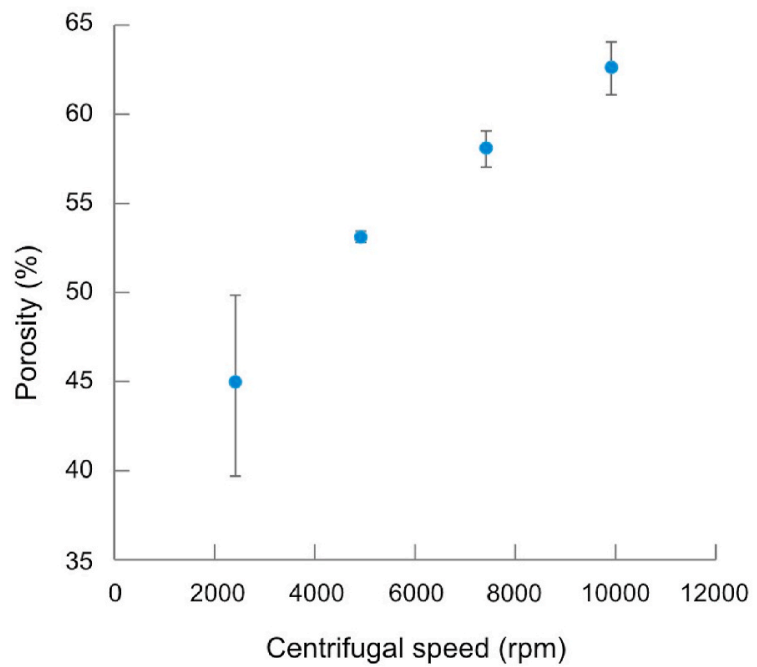

Fig. 8. Porosity content (\%) vs. centrifugal speed (rpm) after infiltration of the epoxy into the YSZ samples. (c) (2020) J. Seuba et al. (10.6084/m9.figshare.15022263) CC BY 4.0 license https://creativecommons.org/lice nses/by/4.0/.

samples with comparable total porosity before infiltration (around $78 \%$ ). The addition of an organic phase-ductile (PCL) or brittle (Epoxy)does not influence the onset of failure, around $2 \%$ strain here, also the yield strength improves with the addition of polymers (Tab 4). The addition of polymers provides additional toughening, as reported above, as the infiltrated samples do not fail in a brittle manner. It is also worth noticing that the rigidity of the samples, observed before crack initiation, increases with the addition of epoxy, more rigid than PCL, for which no increase in rigidity is noted.

Table 4

Variation of porosity and flexural strength of the various composites (YSZ/PCL, YSZ/epoxy, and YSZ/PCL/epoxy).

\begin{tabular}{|c|c|c|c|c|c|}
\hline Sample & Ceramic content (\%) & Polymer content (\%) & Porosity (\%) & $\sigma_{f}(\mathrm{Mpa})$ & Note \\
\hline YSZ & $21.6 \pm 0.9$ & - & $78.4 \pm 3$ & $4.7 \pm 0.8$ & \\
\hline YSZ/PCL & $20.6 \pm 0.7$ & $12.9 \pm 2$ & $66.5 \pm 3$ & $6.5 \pm 1$ & 4 infiltrations \\
\hline YSZ/epoxy & $22.2 \pm 0.9$ & $15.2 \pm 1$ & $62.5 \pm 2$ & $8.8 \pm 2$ & $10000 \mathrm{rpm}$ \\
\hline YSZ/epoxy/PCL & $21.9 \pm 0.6$ & $15.6 \pm 1$ & $62.5 \pm 1$ & $11 \pm 3$ & $10000 \mathrm{rpm}+1$ infiltration $4 \%$ \\
\hline
\end{tabular}




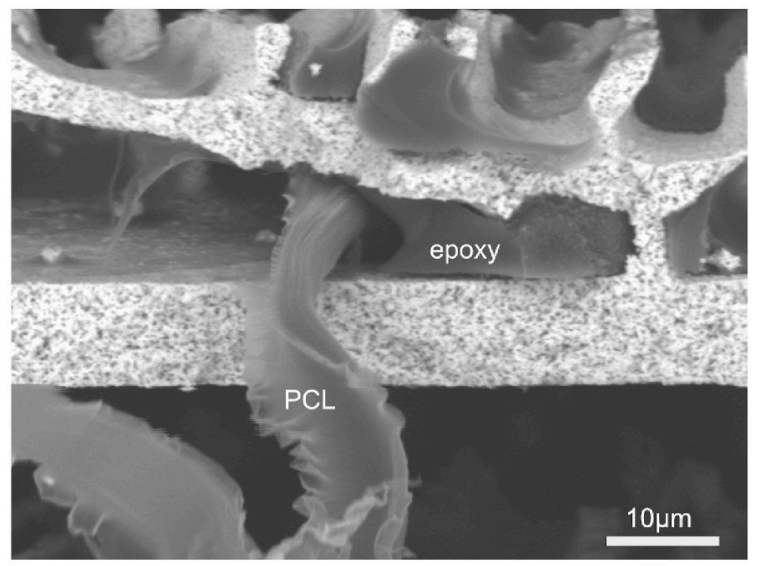

Fig. 9. Close-up view of the fracture surface of a PCL/epoxy/YSZ porous composite. The different fracture behavior of the two polymers can clearly be observed: the epoxy fails in a brittle manner, while the PCL creates elongated fibrils upon failure. (C) (2020) J. Seuba et al. (10.6084/m9.figshare.15022263) CC BY 4.0 license https://creativecommons.org/licenses/by/4.0/.

\subsection{In situ X-ray computed tomography of bending test}

Little is known about the fracture behavior of such porous, anisotropic composites in bending. We previously investigated the role of the polymer phase. In order to better understand the mechanical response of PCL-ceramic composites, we performed a bending test in situ in a X-Ray

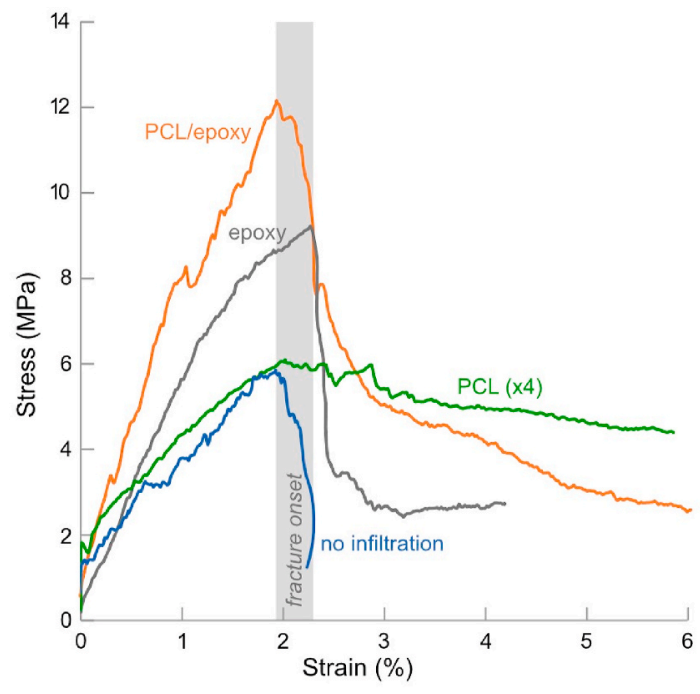

Fig. 10. Stress-strain curves of un-notched bars during 4-points bending for YSZ, PCL/YSZ (4 infiltration cycles), epoxy/YSZ, and PCL/epoxy/YSZ porous composites. The dual infiltration (epoxy + PCL) improves only marginally the crack propagation resistance. The properties of these samples are reported in Table 4. The onset of failure (grey area), around $2 \%$ strain, is on average the same for all samples and is determined by the ceramic scaffold. (C) (2020) J. Seuba et al. (10.6084/m9.figshare.15022263) CC BY 4.0 license https://cre ativecommons.org/licenses/by/4.0/. tomograph. The polymer phase is too light (not enough absorption) to appear on the X-ray images, but the goal here is to understand the role of the ceramic microstructural feature. Fig. 11 shows a 3D reconstruction of the sample, where the notch and the crack and its path can clearly be identified.

The structure of ice-templated materials is typically defined by two features. At a small scale, a lamellar microstructure, replicating the morphology of the ice crystals, is observed. On a short-range, adjacent lamellas are parallel to each other. On a longer range, the lamellas are organized in so-called orientation domains, where all the lamellas are parallel to each other within a domain. Unless specific processing tricks are used (freezing under flow [11], applying magnetic fields during freezing [45], etc.), orientation domains have been observed to be randomly oriented, because of the random selection of the ice crystals in the first instants of freezing. The characteristics of the orientation domains directly impact the mechanical response of the ice-templated materials [36].

The lamellar orientation domains were color-coded based on their orientation (using the Directionality plugin of Fiji [46]) to facilitate the identification of their boundaries. Once the crack is initiated at the tip of the notch, it propagates in different directions depending on the orientation of the domains it encounters, along the boundaries of the orientation domain. This propagation path is intra-domain when the pores in the domain are favorably oriented. A strong change in crack direction is observed at the domain boundary (A marks in Fig. 11). The crack always follows the weakest direction, which is the direction along the adjacent lamellas. Because of the presence of orientation domains, there is not a single weak direction in the material. This extrinsic mechanism, coupled with the crack bridging provided by the PCL, adds an additional toughening mechanism to the material. The role of the orientation domains and the corresponding fracture mode was reported previously, but always in compression [36]. Here, the samples are tested (in situ within the tomograph) in bending. These results are thus complementary to the previous ones, and show that with this solicitation mode, the fracture behavior remains the same.

It is interesting to note that this behavior (crack propagating along adjacent lamellae's) is observed in both ceramics (as reported previously) and ceramic composites (here). While the results reported here show that the addition of a polymer is beneficial for the mechanical properties, the tomography results show that this behavior is not impacted by the addition of polymer. The domain boundaries may force crack deflection and lengthen the crack path, but the lamellae's boundaries still remain the weakest point of the structure. Future work to consolidate these materials should thus probably focus on improving the contact between adjacent lamellas. Several strategies are available for this, including the addition of solutes [47] or anisotropic particles, which can create additional bridges between the adjacent lamellas.

The results that we present in this section are preliminary, and we have to further explore these mechanisms and investigate the particular role of other microstructural features such as the pore/wall ratio, the pore directionality, or the size of the orientation domains. These results nevertheless show that the orientation domains play a role on crack propagation and that the current approach can be used to better understand these mechanisms.

\section{Conclusions}

Here we prepared and characterized porous ceramic/polymer composites with high open porosity contents ( $>70 \%$ ). We characterized the effect of different experimental conditions (infiltration cycles, polymer concentration, centrifugal speed) on the mechanical response. We showed that the nature of the polymer (brittle or ductile) may change 


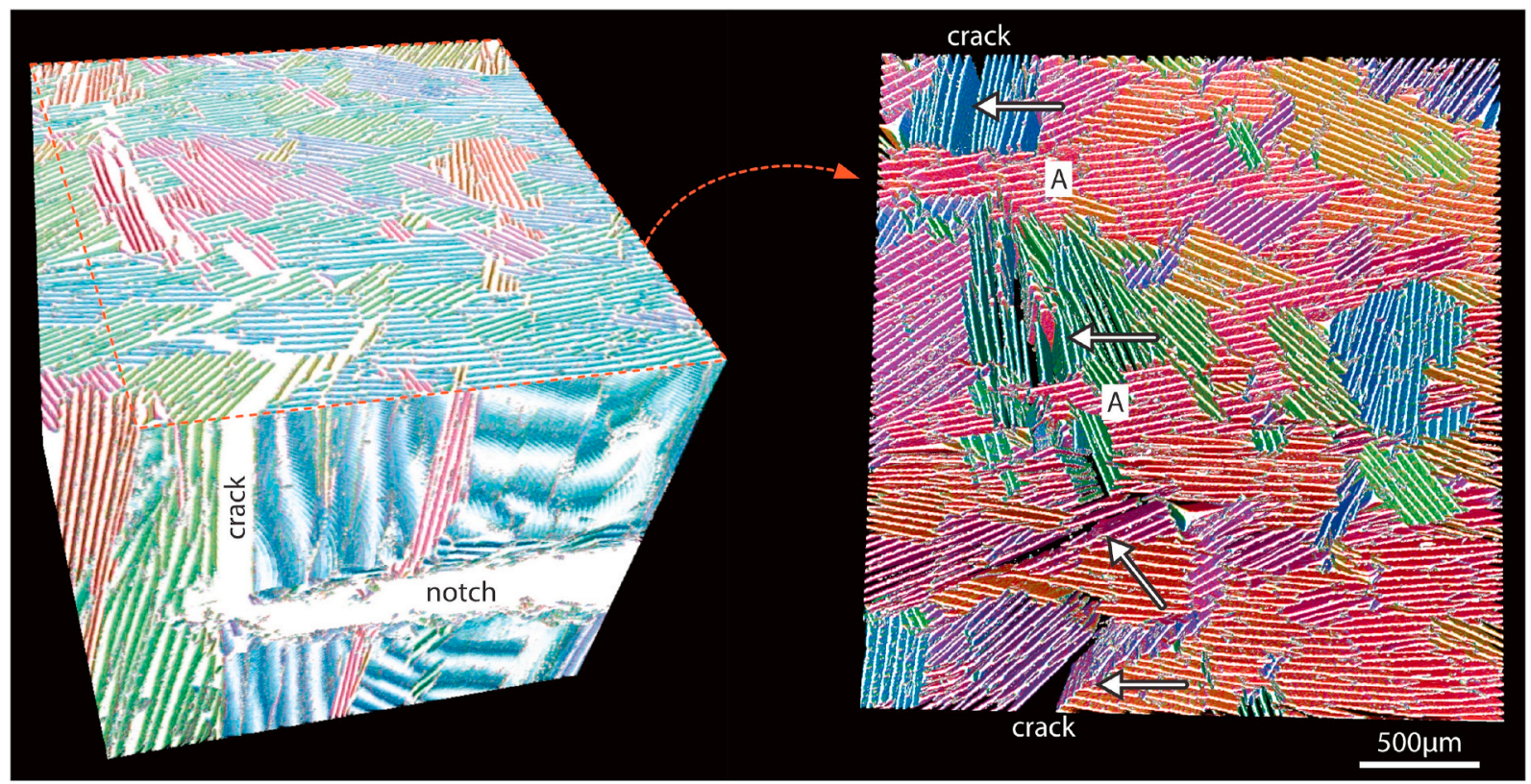

Fig. 11. X-Ray 3D reconstruction of a PCL-alumina composite during the in situ bending test. The color code indicates the local orientation of the domain, which helps delineate the boundaries of the domains. The notch can be seen on the left image. The crack (arrows) can be seen on the images. The crack followed the weakest direction, along the lamellar walls. The existence of domains with different orientations favors the crack deflection. Crack bridging by orientation domains (A), oriented perpendicular to the crack, can be observed. Even with the addition of polymer, the direction along adjacent lamellas remain the weakest point. $\odot$ (2020) J. Seuba et al. (10.6084/m9.figshare.15022263) CC BY 4.0 license https://creativecommons.org/licenses/by/4.0/. (For interpretation of the references to color in this figure legend, the reader is referred to the Web version of this article.)

the fracture behavior of ice-templated porous composites. PCL has a moderate impact only on properties linked to crack initiation (flexural strength, fracture toughness, strain), as already shown for dense ceramic/organic composites by Niebel et al. [48], but a strong impact on the crack propagation (strain energy release and strain to failure). In contrast, epoxy infiltration does not change the fracture behavior (brittle fracture) of porous composites although the flexural strength is slightly improved. No adhesion was found between the polymer and its ceramic substrate. Improving the adhesion by a chemical bounding (grafting) could certainly further improve the mechanical properties. These results are encouraging since the approach is applicable to other systems such as hydroxyapatite/PCL that could be used for synthetic bone substitutes. An increase of the energy stored for the material before total failure could increase the mechanical stability and facilitate their handling and transport, while maintaining an open porosity.

\section{Declaration of interests}

The authors declare that they have no known competing financial interests or personal relationships that could have appeared to influence the work reported in this paper.

\section{Acknowledgements}

The research leading to these results has received funding from the European Research Council under the European Union's Seventh Framework Programme (FP7/2007-2013)/ERC grant agreement 278004 (project FreeCo).

\section{References}

[1] T. Ohji, M. Fukushima, Macro-porous ceramics: processing and properties, Int. Mater. Rev. 57 (2012) 115-131.

[2] K. Okada, T. Isobe, K.-i. Katsumata, Y. Kameshima, A. Nakajima, K.J.D. MacKenzie, Porous ceramics mimicking nature-preparation and properties of microstructures with unidirectionally oriented pores, Sci. Technol. Adv. Mater. 12 (2011), 064701.
[3] A. Julbe, D. Farrusseng, C. Guizard, Porous ceramic membranes for catalytic reactors-overview and new ideas, J. Membr. Sci. 181 (2001) 3-20.

[4] Z. Xing, W. Zhou, F. Du, L. Zhang, Z. Li, H. Zhang, W. Li, Facile synthesis of hierarchical porous tio 2 ceramics with enhanced photocatalytic performance for micropolluted pesticide degradation, ACS Appl. Mater. Interfaces 6 (2014) 16653-16660.

[5] Y. Bi, L. Han, Y. Zheng, Y. Guan, H. Zhang, S. Ge, H. Wang, Q. Jia, Y. Zhang, S. Zhang, Lotus-seedpod-bioinspired 3d superhydrophobic diatomite porous ceramics comodified by graphene and carbon nanobelts, ACS Appl. Mater. Interfaces 10 (2018) 27416-27423.

[6] E.C. Hammel, O.-R. Ighodaro, O.I. Okoli, Processing and properties of advanced porous ceramics: an application based review, Ceram. Int. 40 (2014) $15351-15370$.

[7] R. Bermejo, C. Baudin, R. Moreno, L. Llanes, A. Sanchez-Herencia, Processing optimisation and fracture behaviour of layered ceramic composites with highly compressive layers, Compos. Sci. Technol. 67 (2006) 1930-1938.

[8] S. Bueno, C. Baudín, Composites : Part A Design and processing of a ceramic laminate with high toughness and strong interfaces, Composites Part A 40 (2009) 137-143.

[9] F.J. Martinez-Vazquez, A. Pajares, F. Guiberteau, P. Miranda, Effect of polymer infiltration on the flexural behavior of $\beta$-tricalcium phosphate robocast scaffolds, Materials 7 (2014) 4001-4018.

[10] C. Ferraro, S. Meille, J. Réthoré, N. Ni, J. Chevalier, E. Saiz, Strong and tough metal/ceramic micro-laminates, Acta Mater. 144 (2018) 202-215.

[11] F. Bouville, E. Maire, S. Meille, B. Van de Moortèle, A.J. Stevenson, S. Deville, Strong, tough and stiff bioinspired ceramics from brittle constituents, Nat. Mater. 13 (2014) 508-514.

[12] M.E. Launey, E. Munch, D.H. Alsem, H.B. Barth, E. Saiz, A.P. Tomsia, R.O. Ritchie, Designing highly toughened hybrid composites through nature-inspired hierarchical complexity, Acta Mater. 57 (2009) 2919-2932.

[13] D. Mohamad Yunos, O. Bretcanu, A.R. Boccaccini, Polymer-bioceramic composites for tissue engineering scaffolds, J. Mater. Sci. 43 (2008) 4433-4442.

[14] M. Peroglio, L. Gremillard, J. Chevalier, L. Chazeau, C. Gauthier, T. Hamaide, Toughening of bio-ceramics scaffolds by polymer coating, J. Eur. Ceram. Soc. 27 (2007) 2679-2685.

[15] X. Miao, D.M. Tan, J. Li, Y. Xiao, R. Crawford, Mechanical and biological properties of hydroxyapatite/tricalcium phosphate scaffolds coated with poly(lacticcoglycolic acid), Acta Biomater. 4 (2008) 638-645.

[16] S. Novak, J. Druce, Q.Z. Chen, A.R. Boccaccini, TiO2 foams with poly-(d,1-lactic acid) (PDLLA) and PDLLA/Bioglass $®$ coatings for bone tissue engineering scaffolds, J. Mater. Sci. 44 (2009) 1442-1448.

[17] S. Deville, Ice-templating: processing routes, architectures, and microstructures, in: Freez. Colloids Obs. Princ. Control. Use, Springer International Publishing, 2017, pp. 171-252.

[18] J. Huang, J. Zeng, B. Liang, J. Wu, T. Li, Q. Li, F. Feng, Q. Feng, M.J. Rood, Z. Yan, Multi-arch-structured all-carbon aerogels with superelasticity and high fatigue 
resistance as wearable sensors, ACS Appl. Mater. Interfaces 12 (2020) $16822-16830$.

[19] J. Seuba, S. Deville, C. Guizard, A.J. Stevenson, Gas permeability of ice-templated, unidirectional porous ceramics, Sci. Technol. Adv. Mater. 17 (2016) 313-323.

[20] C. Cai, Z. Wei, Y. Huang, C. Ding, P. Wang, J. Song, L. Deng, Y. Fu, W.H. Zhong, Ultralight programmable bioinspired aerogels with integrated multifunctional surface for self-cleaning, oil absorption, and thermal insulation via Co-assembly, ACS Appl. Mater. Interfaces 12 (9) (2020) 11273-11286, acsami.0c00308.

[21] S. Geng, J. Wei, S. Jonasson, J. Hedlund, K. Oksman, Multifunctional carbon aerogels with hierarchical anisotropic structure derived from lignin and cellulose nanofibers for CO2 capture and energy storage, ACS Appl. Mater. Interfaces (2020) acsami.9b19955.

[22] J.-b. Cheng, H.-b. Zhao, M. Cao, M.-E. Li, A.-n. Zhang, S.-1. Li, Y.-z. Wang, Banana leaf-like C-doped MoS2 aerogels towards excellent microwave absorption performance, ACS Appl. Mater. Interfaces (2020) acsami.0c01841.

[23] S. Deville, E. Saiz, A.P. Tomsia, Freeze casting of hydroxyapatite scaffolds for bone tissue engineering, Biomaterials 27 (2006) 5480-5489.

[24] C. Gaudillere, J. Garcia-Fayos, M. Balaguer, J.M. Serra, Enhanced oxygen separation through robust freeze-cast bilayered dual-phase membranes, Chem. Sus Chem. 7 (2014) 2554-2561.

[25] J.-H. Oh, J. Kim, H. Lee, Y. Kang, I.-K. Oh, Directionally antagonistic graphene oxide-polyurethane hybrid aerogel as a sound absorber, ACS Appl. Mater. Interfaces 10 (2018) 22650-22660.

[26] A. Lichtner, D. Jauffrès, C.L. Martin, R.K. Bordia, Processing of hierarchical and anisotropic porosity LSM-YSZ composites, J. Am. Ceram. Soc. 96 (2013) $2745-2753$.

[27] H. Zhai, P. Xu, M. Ning, Q. Cheng, J. Mandal, Y. Yang, A flexible solid composite electrolyte with vertically aligned and connected ion-conducting nanoparticles for lithium batteries, Nano Lett. 17 (2017) 3182-3187.

[28] J. Seuba, S. Deville, C. Guizard, A.J. Stevenson, Mechanical properties and failure behavior of unidirectional porous ceramics, Sci. Rep. 6 (2016) 1-11.

[29] S. Deville, E. Saiz, R.K. Nalla, A.P. Tomsia, Freezing as a path to build complex composites, Science 311 (2006) 515-518.

[30] J. Roleček, D. Salamon, Z. Chlup, Mechanical properties of hybrid composites prepared by ice-templating of alumina, J. Eur. Ceram. Soc. 37 (2017) 4279-4286.

[31] S. Al-Jawoosh, A. Ireland, B. Su, Fabrication and characterisation of a novel biomimetic anisotropic ceramic/polymer-infiltrated composite material, Dent. Mater. 34 (2018) 994-1002.

[32] R. Chen, M.B. Johnson, K.P. Plucknett, M.-A. White, Thermal conductivity of tunable lamellar aluminum oxide/polymethyl methacrylate hybrid composites, J. Mater. Res. 27 (2012) 1869-1876.

[33] M. Petrini, M. Ferrante, B. Su, Fabrication and characterization of biomimetic ceramic/polymer composite materials for dental restoration, Dent. Mater. 29 (2013) 375-381.
[34] S. Flauder, R. Sajzew, F.A. Müller, Mechanical properties of porous $\beta$-tricalcium phosphate composites prepared by ice-templating and poly(-caprolactone) impregnation, ACS Appl. Mater. Interfaces 7 (2015) 845-851.

[35] S. Deville, E. Maire, A. Lasalle, A. Bogner, C. Gauthier, J. Leloup, C. Guizard, In situ $\mathrm{X}$-ray radiography and tomography observations of the solidification of aqueous alumina particle suspensions-Part I: initial instants, J. Am. Ceram. Soc. 92 (2009) 2489-2496.

[36] A. Lichtner, D. Roussel, D. Jauffrès, C.L. Martin, R.K. Bordia, Effect of macropore anisotropy on the mechanical response of hierarchically porous ceramics, J. Am. Ceram. Soc. 99 (2016) 979-987.

[37] S. Deville, Ice-templated materials: polymers, ceramics, metals and their composites, in: Freez. Colloids Obs. Princ. Control. Use, Springer International Publishing, 2017, pp. 253-350.

[38] J.-Y. Buffiere, E. Maire, J. Adrien, J.-P. Masse, E. Boller, In situ experiments with X ray tomography: an attractive tool for experimental mechanics, Exp. Mech. 50 (2010) 289-305.

[39] M. Peroglio, L. Gremillard, C. Gauthier, L. Chazeau, S. Verrier, M. Alini, J. Chevalier, Mechanical properties and cytocompatibility of poly(e-caprolactone)infiltrated biphasic calcium phosphate scaffolds with bimodal pore distribution, Acta Biomater. 6 (2010) 4369-4379.

[40] T.P. Niebel, F. Bouville, D. Kokkinis, A.R. Studart, Role of the polymer phase in the mechanics of nacre-like composites, J. Mech. Phys. Solid. (2016).

[41] F.J. Martinez-Vazquez, F.H. Perera, I. Van Der Meulen, A. Heise, A. Pajares, P. Miranda, Impregnation of $\beta$-tricalcium phosphate robocast scaffolds by in situ polymerization, J. Biomed. Mater. Res. 101 (2013) 3086-3096.

[42] R.K. Nalla, J.H. Kinney, R.O. Ritchie, Mechanistic fracture criteria for the failure of human cortical bone, Nat. Mater. 2 (2003) 164-168.

[43] R.K. Nalla, J.S. Stölken, J.H. Kinney, R.O. Ritchie, Fracture in human cortical bone: local fracture criteria and toughening mechanisms, J. Biomech. 38 (2005) $1517-1525$.

[44] J.D. Currey, Role of collagen and other organics in the mechanical properties of bone, Osteoporos. Int. 14 (2003) 29-36.

[45] M.M. Porter, P. Niksiar, J. McKittrick, Microstructural control of colloidal-based ceramics by directional solidification under weak magnetic fields, J. Am. Ceram. Soc. 99 (2016) 1917-1926.

[46] J. Schindelin, I. Arganda-Carreras, E. Frise, V. Kaynig, M. Longair, T. Pietzsch, S. Preibisch, C. Rueden, S. Saalfeld, B. Schmid, et al., Fiji: an open-source platform for biological-image analysis, Nat. Methods 9 (2012) 676-682.

[47] E. Munch, E. Saiz, A.P. Tomsia, S. Deville, Architectural control of freeze-cast ceramics through additives and templating, J. Am. Ceram. Soc. 92 (2009) 1534-1539.

[48] T.P. Niebel, F. Bouville, D. Kokkinis, A.R. Studart, Role of the polymer phase in the mechanics of nacre-like composites, J. Mech. Phys. Solid. 96 (2016) 133-146. 